\title{
Impaired macrophage phagocytosis of bacteria in severe asthma
}

\author{
Zhike Liang ${ }^{1,2}$, Qingling Zhang ${ }^{1,2}$, Catherine MR Thomas ${ }^{1}$, Kirandeep K Chana ${ }^{1}$, David Gibeon ${ }^{1}$, Peter J Barnes ${ }^{1}$, \\ Kian Fan Chung ${ }^{1}$, Pankaj K Bhavsar ${ }^{1,3^{*}}$ and Louise E Donnelly ${ }^{1}$
}

\begin{abstract}
Background: Bacteria are frequently cultured from sputum samples of severe asthma patients suggesting a defect in bacterial clearance from the airway. We measured the capacity of macrophages from patients with asthma to phagocytose bacteria.

Methods: Phagocytosis of fluorescently-labelled polystyrene beads, Haemophilus influenzae or Staphylococcus aureus by broncholaveolar lavage alveolar macrophages (AM) and by monocyte-derived macrophages (MDM) from non-asthmatics, mild-moderate and severe asthmatic patients was assessed using fluorimetry.

Results: There were no differences in phagocytosis of polystyrene beads by AMs or MDMs from any of the subject groups. There was reduced phagocytosis of Haemophilus influenzae and Staphylococcus aureus in MDMs from patients with severe asthma compared to non-severe asthma ( $p<0.05$ and $p<0.01$, respectively) and healthy subjects ( $p<0.01$ and $p<0.001$, respectively). Phagocytosis of Haemophilus influenzae and Staphylococcus aureus by AM was also reduced in severe asthma compared to normal subjects $(p<0.05)$. Dexamethasone and formoterol did not suppress phagocytosis of bacteria by MDMs from any of the groups.

Conclusions: Persistence of bacteria in the lower airways may result partly from a reduced phagocytic capacity of macrophages for bacteria. This may contribute to increased exacerbations, airway colonization and persistence of inflammation.
\end{abstract}

Keywords: Macrophages, Phagocytosis, Staphylococcus aureus, Haemophilus influenzae, Asthma

\section{Introduction}

Patients with asthma are usually well-controlled with inhaled corticosteroids (CS) and long-acting $\beta_{2}$-agonists, but a proportion of patients, described as severe asthmatics, continue to experience uncontrolled asthma in spite of these treatments [1]. These patients consume a significant proportion of medical resources in terms of pharmacological treatments, hospital admissions or use of emergency services, and time off work or school [2]. Respiratory infections are often associated with wheezing episodes and may also impact on the development and severity of asthma. Viral and bacterial infections or colonization with bacteria could lead to chronic lower airway inflammation, impaired

\footnotetext{
* Correspondence: p.bhavsar@imperial.ac.uk

${ }^{1}$ Airway Disease, National Heart and Lung Institute, Imperial College London, \& Biomedical Research Unit, Royal Brompton \& Harefield NHS Trust, London SW3, UK

${ }^{3}$ National Heart \& Lung Institute, Dovehouse St, London SW3 6LY, UK

Full list of author information is available at the end of the article
}

mucociliary clearance, increased mucus production and worsening of asthma $[3,4]$. Both viral and bacterial infections have been recognized as drivers of asthma exacerbations [5]. Various bacterial species have been cultured from sputum samples of patients during exacerbations [6], and also during a stable period in moderate-to-severe asthma patients [7,8]. Gram-positive Staphylococcus aureus and Gram-negative Haemophilus influenzae were two of the most common bacterial species cultured from induced sputum of patients with severe asthma [8]. The more sensitive technique of $16 \mathrm{~S}$ ribosomal RNA microarray to detect bacterial species in the lower airways has revealed an increase in bacterial burden and diversity in patients with mild-to-moderate asthma compared to nonasthmatic individuals $[9,10]$. Thus, there appears to be an increased propensity for asthmatic subjects to carry more bacterial pathogens in their lower airways. 
Macrophages produce a variety of cytokines and mediators that are vital for immune and inflammatory responses in their response with external agents. Macrophages are also important for the removal of particulates and bacteria from the airways [11]. This removal of potentially pathogenic micro-organisms via phagocytosis is essential for maintaining a non-pathogenic environment within the lung. However, the phagocytic capacity of macrophages for bacteria may be impaired in various pulmonary conditions. Thus, lung macrophages from children with severe asthma showed reduced phagocytic responses to Staphylococcus aureus [12]. Similarly, defective efferocytosis by AMs from severe asthmatics but not from mildmoderate asthmatics has also been reported [13]. This defect has been postulated to underlie the chronic inflammatory state due to the accumulation of bacteria and apoptotic and necrotic cells in the airways. In chronic obstructive pulmonary disease (COPD), a number of studies have shown defects in both bacterial clearance $[14,15]$ and efferocytosis [16] indicating impaired macrophage innate responses.

We hypothesize that alveolar macrophages (AMs) and macrophages derived from blood monocytes (MDMs) from subjects with asthma may show impaired phagocytosis of Haemophilus influenzae and Staphlycoccus aureus when compared to non-asthmatic subjects. In addition, we examined the potential effects of the asthma treatments, corticosteroids and $\beta$-adrenergic agonists, on these phagocytic responses in-vitro.

\section{Methods}

\section{Study participants}

Patients with asthma were recruited from the Asthma Clinic of the Royal Brompton Hospital, London. All patients demonstrated either an improvement in $\mathrm{FEV}_{1}$ of $>12 \%$ baseline $\mathrm{FEV}_{1}$ after inhaling $400 \mu \mathrm{g}$ salbutamol aerosol or bronchial hyper-responsiveness defined by a concentration of methacholine provoking a fall in $\mathrm{FEV}_{1}$ of $20 \%$ or more $\left(\mathrm{PC}_{20}\right)$ of $<8 \mathrm{mg} / \mathrm{ml}$. Current and exsmokers of $>5$ pack-years were excluded. Patients on steroid-sparing agents such as methotrexate, those with a concurrent diagnosis of clinical bronchiectasis or with a respiratory tract infection requiring antibiotic treatment within 6 weeks of enrolment were excluded.

Severe asthmatics were defined according to the American Thoracic Society's major criteria of needing either continuous or near-continuous oral corticosteroids or high dose inhaled corticosteroids $(2,000 \mu \mathrm{g}$ beclomethasone-equivalent per day or more) or both in order to achieve a level of mildmoderate persistent asthma, and also by the presence of 2 or more minor criteria of asthma control [17]. Patients with non-severe asthma were those who did not fall into the severe asthma category and who used up to $1000 \mu \mathrm{g}$ inhaled beclomethasone or equivalent dosage per day with well-controlled asthma. Healthy volunteers with no diagnosis of asthma and with a negative $\mathrm{PC}_{20}(>16 \mathrm{mg} / \mathrm{ml})$ were also recruited. The study protocol was approved by the Ethics Committee of Royal Brompton \& Harefield NHS Trust/National Heart \& Lung Institute, London UK. All volunteers gave their written informed consent.

\section{Monocyte isolation and MDM differentiation}

Peripheral blood mononuclear cells (PBMCs) were isolated from $80 \mathrm{ml}$ venous blood using Ficoll-Hypaque-Plus. PBMCs and re-suspended in MDM complete media (RPMI-1640 supplemented with 10\% (v/v) FCS, $100 \mathrm{U} / \mathrm{ml}$ penicillin, $100 \mu \mathrm{g} / \mathrm{ml}$ streptomycin, $2 \mathrm{mM}$ L-glutamine), at $1 \times 10^{6}$ cells $/ \mathrm{ml}$ and seeded on 96 -well black plates $\left(10^{5}\right.$ cells/well) for $2 \mathrm{~h}$ at $37^{\circ} \mathrm{C}, 5 \%(\mathrm{v} / \mathrm{v}) \mathrm{CO}_{2}$ to allow monocytes to adhere to the plate. Non-adherent cells were aspirated and monocytes were incubated with fresh complete media containing GM-CSF (2 ng/ml; R\&D Systems, Abingdon, UK). Monocytes were incubated at $37^{\circ} \mathrm{C}$, $5 \%(\mathrm{v} / \mathrm{v}) \mathrm{CO}_{2}$ for 12 days to allow full differentiation into MDMs; fresh media containing GM-CSF were replenished on days 4 and $7[15,18,19]$.

\section{Fibreoptic bronchoscopy and alveolar macrophage isolation}

Fibreoptic bronchoscopy was performed using topical anaesthesia with lignocaine to the upper and lower airways under conscious sedation with intravenous midazolam. Warmed $0.9 \%(\mathrm{w} / \mathrm{v}) \mathrm{NaCl}$ solution $(50 \mathrm{ml} \times 4)$ was instilled into the right middle lobe and bronchoalveolar lavage (BAL) fluid was recovered by gentle hand suction. BAL fluid was centrifuged (400 g for $10 \mathrm{~min}$ ) and the resultant cell pellet washed with Hanks' balanced salt solution (HBSS). Cells were then suspended in culture media (RPMI-1640, containing 10\% (v/v) foetal calf serum (FCS), $100 \mathrm{U} / \mathrm{ml}$ penicillin, $100 \mu \mathrm{g} / \mathrm{ml}$ streptomycin, $2.5 \mu \mathrm{g} / \mathrm{ml}$ amphotericin, $2 \mathrm{mM}$ L-glutamine). Cytospins were prepared and stained with Diff Quick stain (Harleco, Gibbstown, NJ, USA) for differential cell counts. Alveolar macrophages (AMs) were purified by adhesion to the plastic well for $4 \mathrm{~h}$ and then cultured overnight prior to experimentation.

\section{Phagocytosis assay}

Phagocytosis was measured as described previously [15]. AMs and MDMs were exposed, for $4 \mathrm{~h}$, to fluorescentlylabelled polystyrene beads ( $2 \mu \mathrm{M}$ diameter) at a concentration of $50 \times 10^{6}$ beads $/ \mathrm{ml}$ or to heat-killed non-typeable $H$. influenzae or to S. aureus, all labelled with Alexa-Fluor 488 conjugate (Invitrogen, Paisley, Scotland). AMs and MDMs were washed with Dulbecco-phosphate buffered saline and extracellular fluorescence was quenched with $1 \%(\mathrm{w} / \mathrm{v})$ trypan blue at room-temperature. Trypan blue was aspirated and phagocytosis of fluorescent-labeled 
beads and bacteria by AMs or MDMs was measured using a Fluostar Optima fluorimeter (BMG LabTech, Aylesbury, Buckinghamshire) at excitation wavelength of $480 \mathrm{~nm}$ and emission wavelength of $520 \mathrm{~nm}$. Data were expressed as relative fluorescent units (RFU). In order to determine that the beads or bacteria were being internalised, cells were exposed to cytochalasin D $(5 \mu \mathrm{g} / \mathrm{ml})$ for $30 \mathrm{~min}$, prior to incubation with bacteria.

Confocal microscopy was used to visualize whether the beads or bacteria were internalised. MDM $\left(2 \times 10^{5}\right.$ cells $)$ were cultured on well Lab-tek Permanox chamber slides and phagocytosis performed as described above. Cells were then incubated at $37^{\circ} \mathrm{C}$ in $5 \%$ (v/v) $\mathrm{CO}_{2}$ with CellTracker Red CMPTX dye (12.5 $\mu \mathrm{M}$; Invitrogen, Paisley, Scotland) for $45 \mathrm{~min}$ to stain the cytoplasm. Cells were then fixed with $4 \%(\mathrm{w} / \mathrm{v})$ paraformaldehyde. The nuclei were stained by incubation with 4'6-diamidino- 2-phenylindole dihydrochloride (DAPI; $250 \mu \mathrm{M}$ ) for $3 \mathrm{~min}$. Cells were viewed on a confocal microscope with Krypton-Argon laser fluorescence detector.

\section{Cell viability}

Cell viability, as determined by metabolic activity, was performed using an MTT (3-(4,5-dimethylthiazol-2-yl)- 2, 5 -diphenyltetrazolium bromide) assay.

\section{Data analysis}

Results are expressed as mean \pm SEM. A Kruskal-Wallis test or Dunnett's test was used for multi-group comparisons as appropriate. Differences between the effects of dexamethasone or formoterol or dexamethasone and formoterol treatment were analysed using Wilcoxon paired t-test. A Mann-Whitney test was also used where appropriate. Correlations were determined using Spearman rank correlation coefficient. A p value of $<0.05$ was considered significant.

\section{Results}

\section{Participant characteristics}

Severe asthmatics had lower $\mathrm{FEV}_{1}$ (\% predicted) and FVC (\% predicted) compared to both non-severe asthmatics and normal subjects (Table 1). They were also on higher doses of inhaled corticosteroids and reported a greater frequency of exacerbations. Of 14 patients with severe asthma recruited to the MDM study (Table 1), 10 were on daily oral prednisolone. In the severe asthmatics recruited to the AM study (Table 2), there was a trend towards higher eosinophil and neutrophils counts in BAL compared to both healthy and non-severe asthmatic subjects. Three subjects had studies performed on AMs and MDMs.

\section{Phagocytosis by MDMs}

Having established the assay conditions, MDMs from normal subjects and patients with non-severe and severe asthma were exposed to fluorescently-labeled beads or bacteria. There was no difference in phagocytosis of beads between the groups (Figure 1A). However, there was impaired phagocytosis of fluorescently-labelled $H$. influenzae by MDMs from severe asthmatics compared to cells from non-severe asthmatic patients $(\mathrm{p}<0.05)$ and normal subjects $(\mathrm{p}<0.01$; Figure $1 \mathrm{~B})$. MDM phagocytosis of fluorescently-labelled S. aureus was also impaired in severe asthma compared to non-severe asthma $(\mathrm{p}<0.01)$ and normal subjects $(\mathrm{p}<0.001)$. There was no difference in the ability of MDMs from non-severe asthmatics to phagocytose either bacterial species compared to normal subjects.

\section{Phagocytosis by alveolar macrophages}

AMs from all subject groups had a similar capacity to phagocytose beads (Figure 2A). AMs from severe asthmatic patients exhibited a reduced capacity to phagocytose bacteria similar to that observed in MDMs (Figure 2B, 2C).

Table 1 Characteristics of subjects in monocyte-derived macrophage study

\begin{tabular}{|c|c|c|c|}
\hline & Normal & Non-severe asthma & Severe asthma \\
\hline Number & 14 & 14 & 14 \\
\hline $\operatorname{Sex}(F: M)$ & $6: 8$ & $8: 6$ & $9: 5$ \\
\hline Age (years) & $39.6 \pm 2.7$ & $45.9 \pm 3.6$ & $48.6 \pm 2.9$ \\
\hline Atopy ${ }^{\#}$ & $2 / 14$ & $10 / 14$ & $14 / 14$ \\
\hline Duration of asthma (years) & 0 & $33.1 \pm 4.0$ & $37.9 \pm 4.6$ \\
\hline Exacerbations in past year & 0 & $1.57 \pm 0.48$ & $3.78 \pm 0.26^{* * *}$ \\
\hline $\mathrm{FEV}_{1}(\%$ predicted $)$ & $98.31 \pm 3.28$ & $83.40 \pm 3.41$ & $68.24 \pm 4.29^{* *}$ \\
\hline FVC (\% predicted) & $97.00 \pm 3.16$ & $95.51 \pm 3.70$ & $81.99 \pm 2.65^{* *}$ \\
\hline Oral prednisolone $(\mathrm{mg} / \mathrm{d})$ & 0 & 0 & $14.50 \pm 3.0^{* * *}(n=10)$ \\
\hline Inhaled cortico-steroid, BDP equivalent ( $\mu \mathrm{g} /$ day) & 0 & $971 \pm 203(n=11)$ & $2257 \pm 321^{* *}(n=14)$ \\
\hline
\end{tabular}

Abbreviations: BDP Beclomethasone dipropionate, $F E V$, forced expiratory volume in $1 \mathrm{sec}, F$ Female, FVC forced vital capacity, $M$ Male.

\#Atopy defined as positive skin prick test to one or more aeroallergens.

Data shown as mean \pm SEM. ${ }^{* *} \mathrm{p}<0.01,{ }^{* * *} \mathrm{p}<0.001$ compared to non-severe asthma. 
Table 2 Characteristics of subjects in the alveolar macrophage study

\begin{tabular}{|c|c|c|c|}
\hline & Normal & Non-severe asthma & Severe asthma \\
\hline$n$ & 7 & 6 & 8 \\
\hline Sex (F:M) & $2: 5$ & $3: 3$ & $5: 3$ \\
\hline Age (years) & $39 \pm 5.6$ & $34.7 \pm 6.0$ & $43.75 \pm 29$ \\
\hline Atopy $^{\#}$ & $1 / 7$ & $6 / 6$ & $6 / 8$ \\
\hline Duration of asthma (years) & 0 & $25.2 \pm 5.9$ & $35.8 \pm 5.2$ \\
\hline Exacerbation in past year & 0 & $0.33 \pm 0.33$ & $3.25 \pm 0.41^{* * *}$ \\
\hline $\mathrm{FEV}_{1}(\%$ predicted $)$ & $94.71 \pm 15.7$ & $83.08 \pm 4.25$ & $79.69 \pm 4.95$ \\
\hline FVC (\% predicted) & $95.27 \pm 14.65$ & $97.43 \pm 7.55$ & $89.11 \pm 4.35$ \\
\hline Oral prednisolone (mg/day) & 0 & 0 & $8.13 \pm 4.8(n=3)$ \\
\hline Inhaled corticosteroid BDP equivalent ( $\mu \mathrm{g} /$ day) & 0 & $600 \pm 263$ & $2200 \pm 414^{*}$ \\
\hline Total BAL count $\left(\times 10^{6}\right)$ & $10.7 \pm 3.8$ & $8.67 \pm 3$ & $7.3 \pm 1.9$ \\
\hline Cells $/ \mathrm{ml}\left(\times 10^{3}\right)$ & $85 \pm 24.4$ & $74 \pm 24.3$ & $63.8 \pm 18.9$ \\
\hline Lymphocyte (\%) & $18.6 \pm 7$ & $7.9 \pm 1.4$ & $5.12 \pm 1.6$ \\
\hline Eosinophil (\%) & $0.6 \pm 0.2$ & $2.04 \pm 1.2$ & $4.14 \pm 2.4$ \\
\hline Macrophage (\%) & $76.6 \pm 7.7$ & $88.2 \pm 1.7$ & $84.6 \pm 12.4$ \\
\hline Neutrophil (\%) & $2.97 \pm 1.2$ & $1.37 \pm 0.4$ & $5.6 \pm 2$ \\
\hline
\end{tabular}

Abbreviations: BAL Bronchoalveolar lavage, BDP Beclomethasone dipropionate, $F$ Female, $F E V$ forced expiratory volume in 1 sec, $F V C$ forced vital capacity, $M$ male.

\#Atopy defined as positive skin prick test to one or more common aeroallergens.

Data shown as mean \pm SEM. ${ }^{*} \mathrm{p}<0.05,{ }^{* * *} \mathrm{p}<0.001$ compared to non-severe asthma.

There was impaired phagocytosis of fluorescently-labelled $H$. influenzae in severe asthma compared to normal subjects (Figure 2B; p $<0.05$ (Kruskal-Wallis, post-hoc test)); for $S$. aureus, this impairment did not reach significance. However, there was a significant difference between the phagocytic response to $S$. aureus when healthy subjects were directly compared to severe asthmatics $(\mathrm{p}<0.01$; Mann-Whitney).

\section{Phagocytosis, $\mathrm{FEV}_{1}$ and eosinophilia}

Phagocytosis by MDMs of both $H$. influenzae $(r=0.48$, $\mathrm{p}=0.001$, Figure $3 \mathrm{~A})$ and $S$. aureus $(\mathrm{r}=0.40, \mathrm{p}=0.019$, Figure $3 \mathrm{~B}$ ) correlated with $\mathrm{FEV}_{1}$ (\% predicted). Phagocytosis by AMs of $H$. influenzae did not significantly correlate with $\mathrm{FEV}_{1}$ (\% predicted) $(\mathrm{r}=0.4, \mathrm{p}=0.06$, Figure $3 \mathrm{C}$ ) but phagocytosis of $S$. aureus $(r=0.50, p=0.036$, Figure 3D) did positively correlate with $\mathrm{FEV}_{1}$ (\% predicted). For both MDMs and AMs, neither $\mathrm{FEV}_{1} / \mathrm{FVC}$ ratio nor age correlated with any of the phagocytic responses (data not shown). For AMs, there was an inverse correlation between the phagocytic response to $S$. aureus (but not to $H$. influenzae) and the \% eosinophil in BAL fluid ( $r=-0.57$; $\mathrm{p}<0.01$; Additional file 1: Figure S2).

\section{Internalisation of S. aureus by MDM}

Confocal microscopy was used to confirm that particles and bacteria were being internalized (Figure 4) and showed uptake of both beads and $S$. aureus within MDMs (Figure 4A and $\mathrm{B}$ ). In order to further confirm the process of internalization, MDMs were exposed to cytochalasin D $(5 \mu \mathrm{g} / \mathrm{ml})$, an inhibitor of actin filament polymerization, prior to incubation with $S$. aureus (Figure 4C). This led to an inhibition of phagocytosis with $S$. aureus unable to enter the cells, localizing to the outer cell membrane of MDMs. Having established that cytochalasin D prevented phagocytosis, we determined whether the fluorimetric plate reader assay could distinguish between intra-cellular bacteria (phagocytosis) and outer membrane-associated bacteria. Phagocytosis experiments were then performed in the absence and presence of cytochalasin D. Phagocytosis of beads, $H$. influenzae and $S$. aureus was suppressed in MDMs from all patient groups as indicated by the difference in fluorescence units (Figure 4D-F). There was a significant difference for all groups and particles between non- stimulated and Cyto D treated cells (Figure 4D-F).

\section{Effect of dexamethasone on phagocytosis}

In order to investigate whether corticosteroids could influence the phagocytic response, MDMs isolated from normal subjects, and non-severe and asthmatics were exposed to dexamethasone prior to addition of beads or bacteria. Dexamethasone improved phagocytosis of beads and bacteria by MDM from normal subjects and nonsevere asthmatics to a small extent $(\sim 10 \%)$ at low concentrations, reaching significance at $10^{-8} \mathrm{M}$, and also at $10^{-7} \mathrm{M}$ for beads only, but this effect was not seen at higher concentrations of dexamethasone (Figure 5). Dexamethasone did not change the phagocytic response of MDMs obtained from patients with severe asthma. Dexamethasone did not 

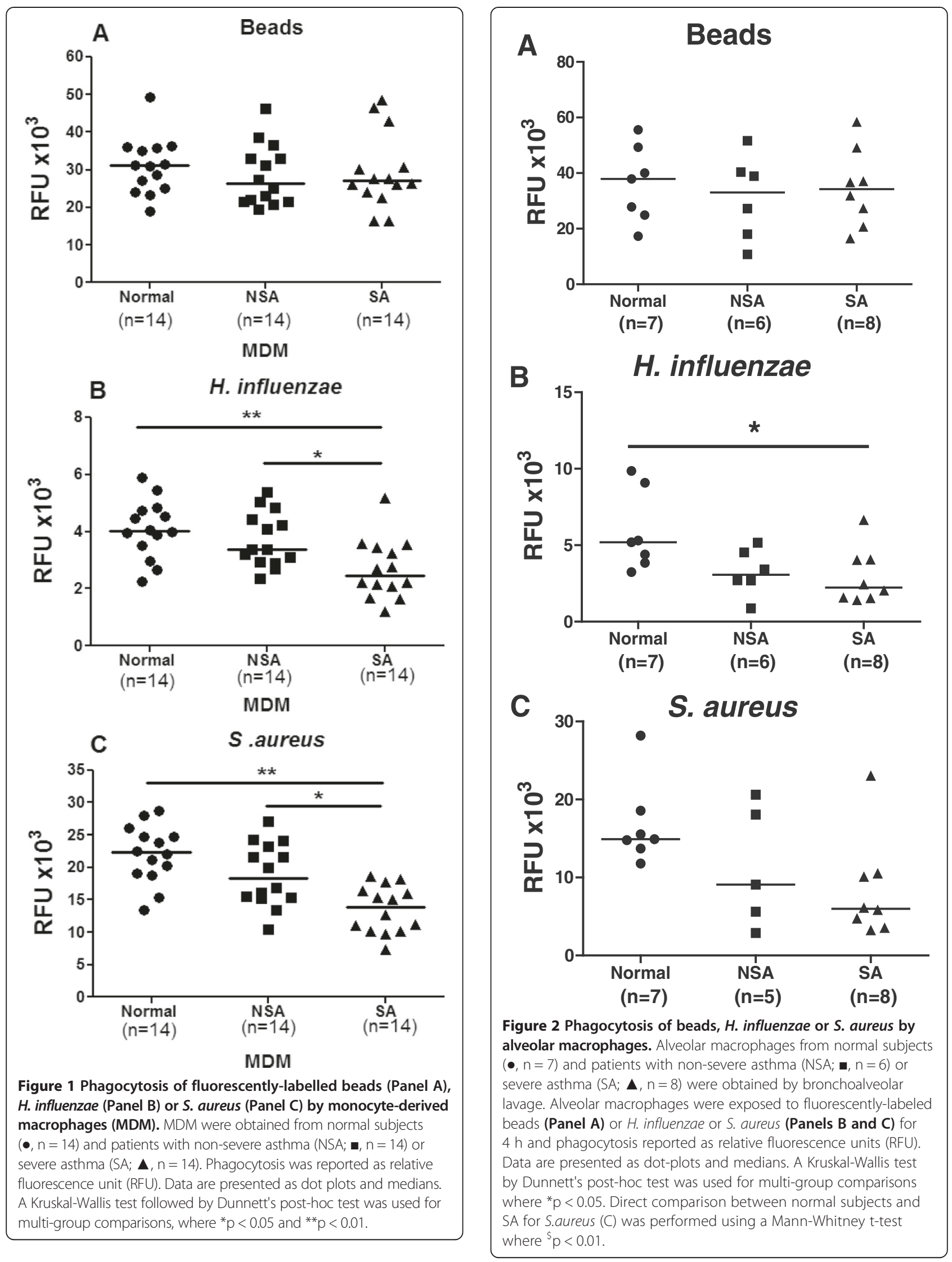


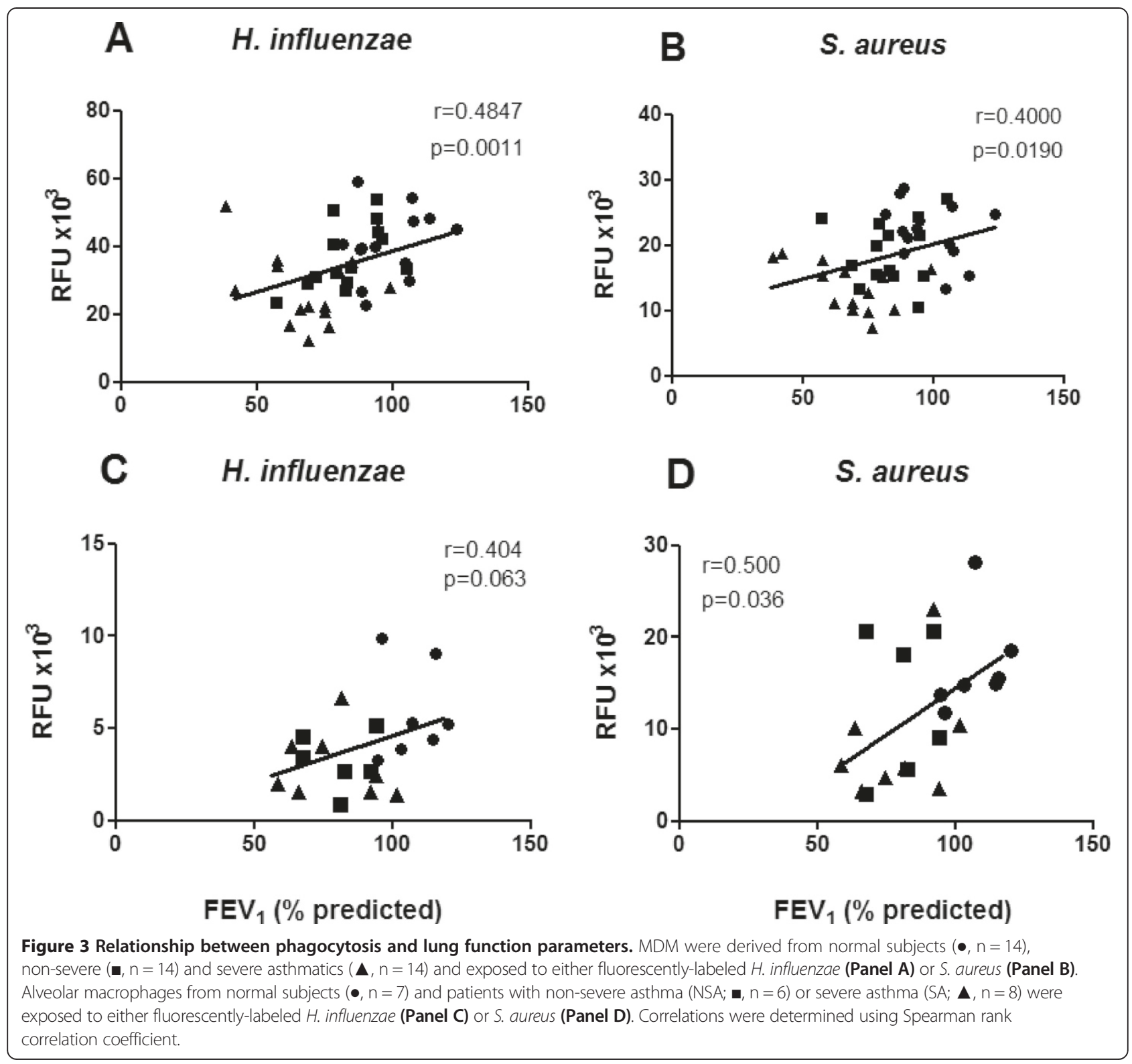

affect cell metabolic activity as measured by MTT assay (Additional file 1: Figure S1A).

\section{Effect of formoterol alone or in combination with dexamethasone}

The effect of the long-acting inhaled $\beta_{2}$-agonist, formoterol, and the combination of dexamethasone and formoterol on phagocytosis of MDMs was investigated. Formoterol alone had no effect on phagocytosis of bacteria by MDMs in any of the subject groups (Figure 6A-B). The combination of formoterol with dexamethasone at $10^{-8} \mathrm{M}$ each caused a small improvement of phagocytosis of $H$. influenzae by MDMs from normal subjects and non-severe asthmatics $(\mathrm{p}<0.05$, Figure 6C), but this was not seen in MDMs from severe asthmatic subjects (Figure 6C and 6D). For phagocytosis of $S$. aureus by MDMs, there was also an improvement with dexamethasone and formoterol at $10^{-8} \mathrm{M}$ for normal individuals $(\mathrm{p}<0.01$, Figure $6 \mathrm{D})$ and for non-severe asthmatics with dexamethasone and formoterol at $10^{-8}$ and $10^{-9} \mathrm{M}(\mathrm{p}<0.05$, Figure $6 \mathrm{D})$. Formoterol did not affect cell metabolic activity as measured by MTT assay (Additional file 1: Figure S1B).

\section{Discussion}

We investigated whether macrophage clearance of bacterial species associated with asthmatic airways were altered in asthma. We showed that there was a reduction in phagocytosis of fluorescently-labelled $H$. influenzae and $S$. aureus by MDMs from patients with severe asthma compared with MDMs from healthy controls; however 


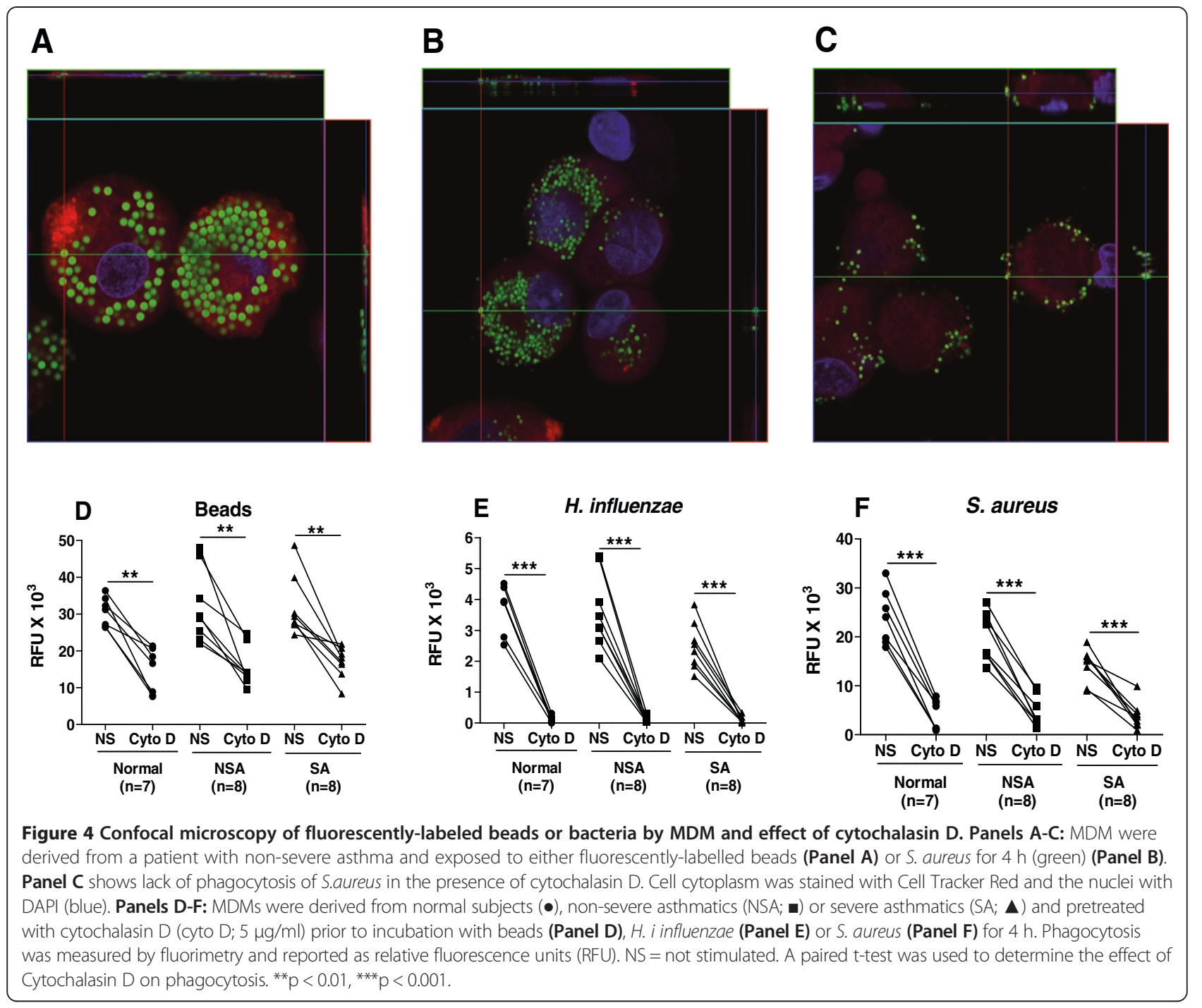

this defect was not apparent in MDMs from non-severe asthmatics. We also showed that alveolar macrophages from severe asthma patients exhibited compromised phagocytic capacities for these bacterial species. However, the phagocytic response of these macrophages and MDMs to polystyrene beads was not altered in cells from patients with asthma, indicating that the defect was related specifically to these bacteria. These results are an extension of previous observations in children, where phagocytosis of inactivated $S$. aureus was impaired in alveolar macrophages from patients with severe asthma and to a lesser extent in those with moderate asthma [12]. This observation may underlie the increased risk of bacterial infections that has been described in patients with stable severe asthma $[8,20]$. In addition, this defect in bacterial phagocytosis may explain partly the presence of the altered microbiome that has been described in the airways of patients with asthma compared with healthy subjects [9]. A similar defect in the phagocytosis of bacterial pathogens by MDMs and AMs from patients with COPD has also been reported [15], also in association with an altered microbiome in the airways of patients with COPD $[9,21]$.

MDMs and macrophages obtained from non-severe asthmatic patients did not show reduced phagocytosis of $H$. influenzae and $S$. aureus compared to normal subjects suggesting that the phagocytic defect was associated with more severe asthma. Severe asthma exhibits a number of similarities with COPD such as the presence of airway neutrophilia [22]. Our results are in line with a recent study showing that macrophages isolated from induced sputum from asthmatic subjects with increased neutrophil counts in the sputum were also less able to phagocytose apoptotic bronchial epithelial cells [23], indicating a defect in the process of efferocytosis in the airways of patients with asthma. The defect in phagocytosis of bacteria could lead to a persistence of airway bacteria resulting in airway neutrophilia through the release 


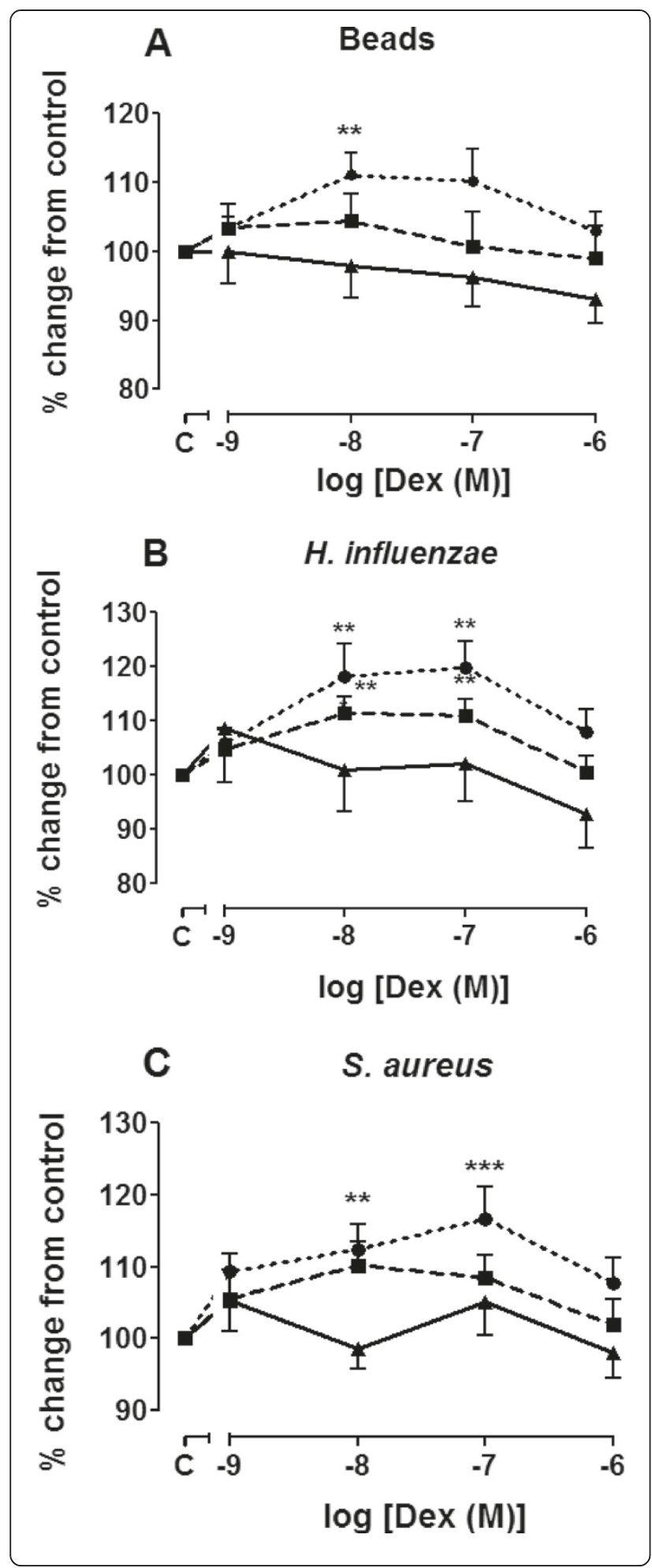

Figure 5 Effect of dexamethasone on phagocytosis by MDM. MDM from normal subjects $(\bullet, n=14)$, non-severe asthmatics $(\boldsymbol{\square}, n=14)$ and severe asthmatics $(\boldsymbol{\Lambda}, \mathrm{n}=14)$ were pre-treated with dexamethasone for $1 \mathrm{~h}$ prior to exposure to fluorescently-labelled beads (Panel A), H. influenzae (Panel B) or S.aureus (Panel C) for 4 h. Phagocytosis was measured by fluorimetry and presented as mean \pm SEM. A Mann-Whitney test was used to compare the effect of given concentration of dexamethasone with that of untreated samples. ${ }^{* *} p<0.01$ and ${ }^{* * *} p<0.001$ compared to untreated cells.

of neutrophilic chemokines such as CXCL8 and possibly to worsening of asthma in terms of severity of symptoms and recurrence of exacerbations. Recent work has indicated that in-vitro infection of lung tissue macrophages with rhinovirus resulted in an impairment of the phagocytosis of bacteria by alveolar macrophages [24]. This mechanism of defective bacterial phagocytosis by the presence of rhinovirus may be relevant to acute severe asthma, where a high percentage of positive bacterial cultures from sputum samples has also been reported [25].

The cellular and molecular mechanisms for this phagocytic defect of macrophages from patients with severe asthma are unclear. Macrophages are important for both innate and acquired immunity in the respiratory tract, and have a pivotal role in lung defense against viruses, bacteria and fungi [26]. The findings of this study indicate that, in severe asthma, an impairment of the ability of alveolar macrophages to phagocytose bacteria could lead to prolonged persistence of bacteria in the airways and lungs, which could contribute to the worsening of asthma control. In a previous study, we showed that the release of pro-inflammatory cytokines from peripheral blood mononuclear cells and alveolar macrophages from patients with asthma, stimulated with lipopolysacharide, was not different from that of patients with non-severe asthma $[27,28]$, indicating that the inflammatory response to one constituent of gram-negative bacteria is not impaired in severe asthma. However, the response of these cells to whole bacteria is not known. Reactive oxygen species production by alveolar macrophages is required for bacterial killing [29], and is also important for phagocytosis. In mice lacking the antioxidant enzyme extracellular superoxide dismutase [30], macrophage phagocytosis of bacteria was impaired, suggesting that removal of reactive oxygen species within alveolar macrophages is required for normal phagocytosis.

There was a positive correlation between airflow obstruction as measured by $\mathrm{FEV}_{1}$ and phagocytosis of bacteria, either $S$. aureus or $H$. influenzae, by alveolar macrophages and MDMs. The link between the reduced bacterial phagocytosis and airflow obstruction remains unclear. Airflow obstruction in severe asthma has been associated with eosinophilic inflammation, duration of asthma and thickening of the airways as measured by high resolution computed tomography [8]. It is possible that the 

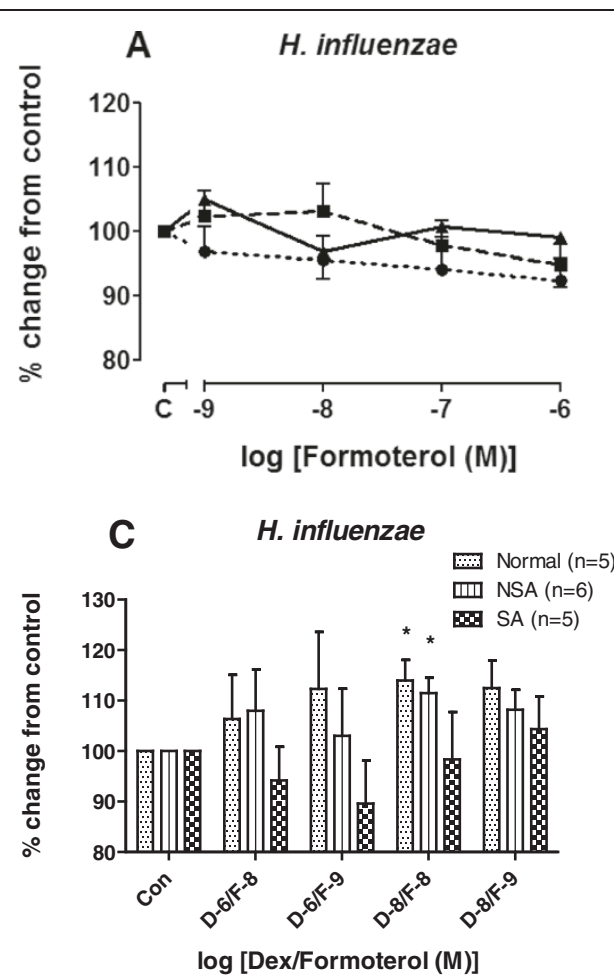

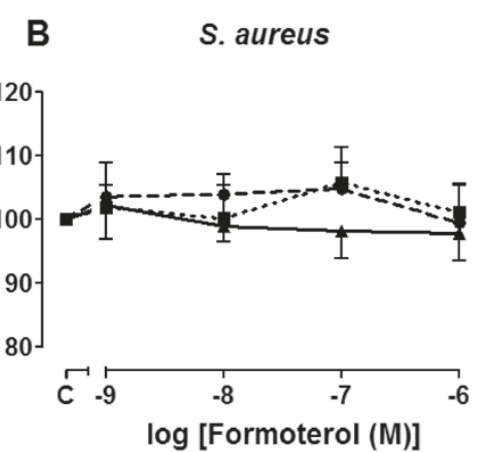

D S. aureus

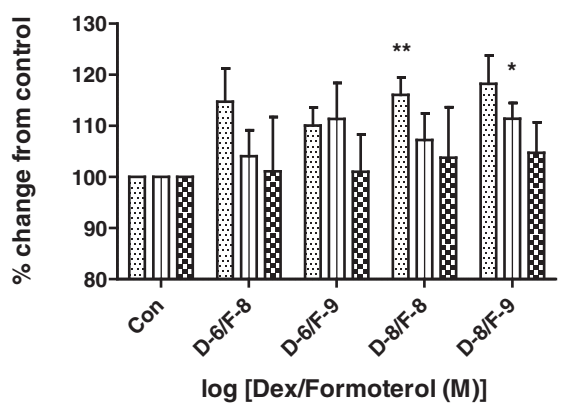

Figure 6 Effect of formoterol alone or in combination with dexamethasone on phagocytosis. MDM were derived from from normal subjects $(\bullet, n=5)$, non-severe asthmatics $(\boldsymbol{\bullet}, n=6)$ and severe asthmatics $(\boldsymbol{\Lambda}, n=5)$ were pre-treated with formoterol in the absence or presence of dexamethasone for $1 \mathrm{~h}$ prior to exposure to $\mathrm{H}$. influenzae (Panels A and C) or S. aureus (Panels B and D) for 4 h. Phagocytosis was measured by fluorimetry and data presented as mean \pm SEM. Differences between the effects of dexamethasone or formoterol or dexamethasone and formoterol treatment were analysed using Wilcoxon paired t-test, where ${ }^{*} \mathrm{p}<0.05$ and ${ }^{* *} \mathrm{p}<0.01$ compared to untreated cells. $\mathrm{D}=$ dexamethasone, $F=$ formoterol.

link may lie with airway wall remodelling, as this has been associated with the presence of chronic airflow obstruction. The negative correlation between the percentage of eosinophils in bronchoalveolar lavage fluid and the phagocytic response to $S$. aureus of macrophages from asthma patients also support a potential role for eosinophilic inflammation. Eosinophlic inflammation is an important source of oxidative stress in asthma [31], and oxidative stress has been linked to defective phagocytosis of bacteria [32].

Inhaled corticosteroids and $\beta$-agonists remain the mainstay of treatment of many patients with asthma [33]. Patients with more severe asthma are usually treated with high doses of these agents. In addition, the majority of the patients with severe asthma in our study were also on oral corticosteroid therapy. However, many patients with severe asthma may not achieve control and this lack of therapeutic response to corticosteroids has been attributed to the development of corticosteroid insensitivity $[27,28]$. Oxidative stress pathways [34] and activation of mitogenactivated protein kinases have been implicated as mechanisms of corticosteroid insensitivity in severe asthma $[27,35]$. Bacterial interactions with epithelial cells and macrophages can activate these pathways and therefore could underlie corticosteroid insensitivity.

Neither dexamethasone nor formoterol had any deleterious effects on the phagocytic response in MDM from any of the subject groups. Dexamethasone alone or combined with formoterol slightly improved the phagocytic response of MDM for both beads and bacteria obtained from healthy subjects but not from those with asthma. The significance of this small increase is unlikely to be clinically relevant. There was also no effect of the phagocytic response towards either $H$. influenzae or S. aureus in severe asthma by dexamethasone or formoterol, which contrasts to the increase in phagocytosis of bacteria by MDMs stimulated by budesonide previously reported in COPD patients [15]. However, in another study, budesonide decreased phagocytosis in alveolar macrophages from healthy never-smoked subjects by decreasing the number of cells with the ability to phagocytose as well as decreasing phagocytic capacity of these cells [36]. These shortterm studies will not categorically exclude the possibility that long-term usage of corticosteroids and long-acting $\beta$-agonists in severe asthma may have a detrimental effect on macrophage phagocytosis. 
A possible shortcoming of the study could be the lower number of subjects recruited to the AM study as a result of the inherent problems associated with collecting BAL samples from severe asthmatics. However, these studies performed in AM were proof of principle studies to confirm, ex vivo, the findings of the MDM study. Moreover, although there are studies showing that macrolides [37] and antifungal agents [38] can improve the phagocytic capabilities of macrophages, our results show that in the presence of antifungal and/or antibacterial agents, AMs and MDMs from patients with asthma continue to display an inherent impaired phagocytic response compared to those from control subjects

In summary, MDMs and AMs from severe asthma patients demonstrate reduced phagocytosis of fluorescentlylabelled $H$. influenzae and S. aureus. This may contribute to the bacterial colonisation of the lower airways and to the propensity for bacterial exacerbations in severe asthma. This defect is unlikely to result from an acute response to corticosteroid or $\beta$-adrenergic therapy. Further work is needed to determine the cellular and molecular basis of this phagocytic defect for bacteria.

\section{Conclusions}

Persistence of bacteria in the lower airways may result partly from a reduced phagocytic capacity of macrophages for bacteria. This may contribute to increased exacerbations, airway colonization and persistence of inflammation.

\section{Additional file}

Additional file 1: Figure S1. Effect of dexamethasone or formoterol on metabolic activity of MDM. MDM from normal subjects, non-severe asthmatics and severe asthmatics were treated with dexamethasone (A) or formoterol (B) for $1 \mathrm{~h}$ and cells assayed for metabolic activity using MTT assay. Figure S2. Relationship between phagocytosis of S. aureus by AM and \% eosinophils in BAL. Alveolar macrophages from normal subjects $(\bullet, n=7)$ and patients with non-severe asthma $(\boldsymbol{\bullet}, n=6)$ or severe asthma $(\boldsymbol{\Lambda}, n=8)$ were exposed to fluorescently-labelled $S$. aureus. Correlations were determined using Spearman's rank correlation coefficient.

\section{Abbreviations}

AM: Alveolar macrophage; BAL: Bronchoalveolar lavage; COPD: Chronic obstructive pulmonary disease; FEV ${ }_{1}$ : Forced expiratory volume in $1 \mathrm{sec}$; FVC: Forced vital capacity; H. influenzae: Haemophilus influenzae; MDM: Monocyte derived macrophage; PBMC: Perpheral blood mononuclear cells; $\mathrm{PC}_{20}$ : Provocative concentration of metacholine causing a $20 \%$ fall in $\mathrm{FEV}_{1} ; \mathrm{S}$. aureus: Staphylococcus aureus.

\section{Competing interests}

PKB has received project grant funding from GlaxoSmithKline. PJB has received project grant funding from GlaxoSmithKline and Astra-Zeneca. KFC has received project grant funding from GlaxoSmithKline and Pfizer. LED has received project grant funding Astra-Zeneca and Pfizer. The other authors have no competing interests.

\section{Authors' contributions}

ZL participated in the design of the study, carried out all assays on MDMs, performed the statistical analysis and drafted the manuscript. QZ participated in the design of the study, and performed assays on AMs. CMRT participated in the design of the study and generated labelled Haemophilus influenzae. KR performed assays on AMs. DG performed bronchoalveolar lavage on subjects for the AM study. PJB participated in the design and coordination of the study. LED participated in the design and coordination of the study and critically revised the manuscript. PKB and KFC conceived the study, participated in the design and coordination of the study and wrote the manuscript. All authors read and approved the final manuscript.

\section{Acknowledgements}

We thank Florence Chow and Sally Meah for the recruitment of patients. This study was supported by the National Institute of Health Research Respiratory Disease Biomedical Research Unit at the Royal Brompton Hospital and Harefield Foundation NHS Trust and Imperial College London. ZK Liang was supported by a grant from Guangzhou Health Bureau, Guangdong Province, China.

\section{Author details}

${ }^{1}$ Airway Disease, National Heart and Lung Institute, Imperial College London, \& Biomedical Research Unit, Royal Brompton \& Harefield NHS Trust, London SW3, UK. ${ }^{2}$ State Key Laboratory of Respiratory Diseases, The First Affiliated Hospital \& Guangzhou First People's Hospital, Guangzhou Medical University, Guangzhou, China. ${ }^{3}$ National Heart \& Lung Institute, Dovehouse St, London SW3 6LY, UK.

Received: 3 February 2014 Accepted: 20 June 2014 Published: 27 June 2014

\section{References}

1. Chung KF, Godard P, Adelroth E, Ayres J, Barnes N, Barnes P, Bel E, Burney P, Chanez P, Connett G, Corrigan C, de Blic J, Fabbri L, Holgate ST, Ind P, Joos G, Kerstjens H, Leuenberger P, Lofdahl C-G, McKenzie S, Magnussen H, Postman, Saetta D, Salmeron S, Silverman M, Sterk P: Difficult/therapy-resistant asthma: the need for an integrated approach to define clinical phenotypes, evaluate risk factors, understand pathophysiology and find novel therapies. ERS Task Force on Difficult/Therapy-Resistant Asthma. European Respiratory Society. Eur Respir J 1999, 13:1198-1208.

2. Moore WC, Bleecker ER, Curran-Everett D, Erzurum SC, Ameredes BT, Bacharier L, Calhoun WJ, Castro M, Chung KF, Clark MP, Dweik RA, Fitzpatrick AM, Gaston B, Hew M, Hussain I, Jarjour NN, Israel E, Lewy BD, Murphy JR, Peters SP, Teague WG, Meyers DA, Busse WW, Wenzel SE: Characterization of the severe asthma phenotype by the National Heart, Lung, and Blood Institute's Severe Asthma Research Program. J Allergy Clin Immunol 2007, 119:405-413.

3. Bisgaard H, Hermansen MN, Buchvald F, Loland L, Halkjaer LB, Bønnelykke K, Brasholt M, Heltberg A, Vissing NH, Thorsen SV, Stage M, Pipper CB: Childhood asthma after bacterial colonization of the airway in neonates. N Eng J Med 2007, 357:1487-1495.

4. Martin RJ, Kraft M, CHU HW, Berns EA, Cassell GH: A link between chronic asthma and chronic infection. J Allergy Clin Immunol 2001, 107:595-601.

5. Jackson DJ, Johnston SL: The role of viruses in acute exacerbations of asthma. J Allergy Clin Immunol 2010, 125:1178-1187.

6. Cazzola M, Matera MG, Blasi F: Macrolide and occult infection in asthma. Curr Opin Pulm Med 2004, 10:7-14.

7. Wood LG, Simpson JL, Hansbro PM, Gibson PG: Potentially pathogenic bacteria cultured from the sputum of stable asthmatics are associated with increased 8-isoprostane and airway neutrophilia. Free Radic Res 2009, 44:146-154.

8. Zhang Q, Illing R, Hui C, Downey K, Carr D, Stearn M, Alshafi K, Menzies-Gow A, Zhong N, Fan Chung K: Bacteria in sputum of stable severe asthma and increased airway wall thickness. Respir Res 2012, 13:35.

9. Hilty M, Burke C, Pedro H, Cardenas P, Bush A, Bossley C, Davies J, Ervine A, Poulter L, Pachter L, Moffatt MF, Cookson WO: Disordered microbial communities in asthmatic airways. PLoS One 2010, 5:8578.

10. Huang YJ, Nelson CE, Brodie EL, Desantis TZ, Baek MS, Liu J, Woyke T, Allgaier M, Bristow J, Wiener-Kronish JP, Sutherland ER, King TS, Litovic N, Martin RJ, Calhoun WJ, Castro M, Denlinger LC, Dimango E, Kraft M, Peters SP, Wasserman SI, Wechsler ME, Boushey HA, Lynch SV: Airway microbiota and bronchial hyperresponsiveness in patients with suboptimally controlled asthma. J Allergy Clin Immunol 2011, 127:372-381.

11. Donnelly LE, Barnes PJ: Defective phagocytosis in airways diseasephagocytic dysfunction and airways disease. Chest 2012, 141:1055-1062. 
12. Fitzpatrick AM, Holguin F, Teague WG, Brown LA: Alveolar macrophage phagocytosis is impaired in children with poorly controlled asthma. J Allergy Clin Immunol 2008, 121:1372-1378.

13. Huynh ML, Malcolm KC, Kotaru C, Tilstra JA, Westcott JY, Fadok VA, Wenzel SE: Defective apoptotic cell phagocytosis attenuates prostaglandin E2 and 15-hydroxyeicosatetraenoic acid in severe asthma alveolar macrophages. Am J Respir Crit Care Med 2005, 172:972-979.

14. Berenson CS, Garlipp MA, Grove LJ, Maloney J, Sethi S: Impaired phagocytosis of nontypeable haemophilus influenzae by human alveolar macrophages in chronic obstructive pulmonary disease. J Infect Dis 2006, 194:1375-1384.

15. Taylor AE, Finney-Hayward TK, Quint JK, Thomas CMR, Tudhope SJ, Wedzicha JA, Barnes PJ, Donnelly LE: Defective macrophage phagocytosis of bacteria in COPD. Eur Respir J 2010, 35:1039-1047.

16. Hodge S, Hodge G, Scicchitano R, Reynolds PN, Holmes M: Alveolar macrophages from subjects with chronic obstructive pulmonary disease are deficient in their ability to phagocytose apoptotic airway epithelial cells. Immunol Cell Biol 2003, 81:289-296.

17. Proceedings of the ATS Workshop on Refractory Asthma. Current Understanding, Recommendations, and Unanswered Questions. Am J Respir Crit Care Med 2000, 162:2341-2351.

18. Winkler AR, Nocka KH, Sulahian TH, Kobzik L, Williams CMM: In vitro modelling of human alveolar macrophage smoke exposure: enhanced inflammation and impaired function. Exp Lung Res 2008, 34:599-629.

19. Akagawa KS: Functional heterogeneity of colony-stimulating factor-induced human monocyte-derived macrophages. Int J Hematol 2002, 76(1):27-34.

20. Wood LG, Simpson JL, Hansbro PM, Gibson PG: Potentially pathogenic bacteria cultured from the sputum of stable asthmatics are associated with increased 8-isoprostane and airway neutrophilia. Free Radic Res 2013, 44(2):146-154.

21. Pragman AA, Kim HB, Reilly CS, Wendt C, Isaacson RE: The lungmicrobiomein moderate and severechronic obstructive pulmonary disease. PLoS One 2012, 7(10):e47305.

22. Jatakanon A, Uasuf C, Maziak W, Lim S, Chung KF, Barnes PJ: Neutrophilic Inflammation in Severe Persistent Asthma. Am J Respir Crit Care Med 1999, 160:1532-1539.

23. Simpson JL, Gibson PG, Yang IA, Upham J, James A, Reynolds PN, Hodge S, AMAZES Study Research Group: Impaired macrophage phagocytosis in non-eosinophilic asthma. Clin Exp Allergy 2013, 43:29-35.

24. Oliver BGG, Lim S, Wark P, Laza-Stanca V, King N, Black JL, Burgess JK, Roth M, Johnston SL: Rhinovirus exposure impairs immune responses to bacterial products in human alveolar macrophages. Thorax 2008, 63:519-525.

25. Cazzola M, Matera MG, Rossi F: Bronchial hyperresponsiveness and bacterial respiratory infections. Clin Ther 1991, 13(1):157-171.

26. Gordon SB, Read RC: Macrophage defences against respiratory tract infections: The immunology of childhood respiratory infections. Br Med Bull 2002, 61:45-61.

27. Bhavsar P, Hew M, Khorasani N, Torrego A, Barnes PJ, Adcock I, Chung KF: Relative corticosteroid insensitivity of alveolar macrophages in severe asthma compared with non-severe asthma. Thorax 2008, 63:784-790.

28. Hew M, Bhavsar P, Torrego A, Meah S, Khorasani N, Barnes PJ, Adcock I, Fan Chung K, National Heart Lung and Blood Institute's Severe Asthma Research Program: Relative corticosteroid insensitivity of peripheral blood mononuclear cells in severe asthma. Am J Respir Crit Care Med 2006, 174:134-141.

29. Oczypok EA, Oury TD, Chu CT: It's a cell-eat-cell world: autophagy and phagocytosis. Am J Pathol 2013, 182:612-622.

30. Manni ML, Tomai LP, Norris CA, Thomas LM, Kelley EE, Salter RD, Crapo JD, Chang LY, Watkins SC, Piganelli JD, Oury TD: Extracellular superoxide dismutase in macrophages augments bacterial killing by promoting phagocytosis. Am J Pathol 2011, 178:2752-2759.

31. Wu W, Samoszuk MK, Comhair SAA, Thomassen MJ, Farver CF, Dweik RA, Kavuru MS, Erzurum SC, Hazen SL: Eosinophils generate brominating oxidants in allergen-induced asthma. J Clin Invest 2000, 105:1455-1463.

32. Thimmulappa RK, Gang X, Kim JH, Sussan TE, Witztum JL, Biswal S: Oxidized phospholipids impair pulmonary antibacterial defenses: Evidence in mice exposed to cigarette smoke. Biochem Biophys Res Commun 2012, 426:253-259.

33. Chung KF, Caramori G, Adcock IM: Inhaled corticosteroids as combination therapy with â-adrenergic agonists in airways disease: present and future. Eur J Clin Pharmacol 2009, 65(9):853-871.
34. Chung KF, Marwick JA: Molecular mechanisms of oxidative stress in airways and lungs with reference to asthma and chronic obstructive pulmonary disease. Ann N Y Acad Sci 2010, 1203:85-91.

35. Marwick JA, Caramori G, Casolari P, Mazzoni F, Kirkham PA, Adcock IM, Chung KF, Papi A: A role for phosphoinositol 3-kinase [delta] in the impairment of glucocorticoid responsiveness in patients with chronic obstructive pulmonary disease. J Allergy Clin Immunol 2010, 125:1146-1153.

36. Zetterlund A, Larsson PH, Müller-Suur C, Palmberg L, Larsson K: Budesonide but not terbutaline decreases phagocytosis in alveolar macrophages. Respir Med 1998, 92:162-166.

37. Nino DF, Cauvi DM, De Maio A: A commonly used antifungal, inhibits fcã receptor-mediated phagocytosis: alteration of fcy receptor glycosylation and gene expression. Shock 2014, 42(1):52-59.

38. Gao X, Ray R, Xiao Y, Ishida K, Ray P: Macrolide antibiotics improve chemotactic and phagocytic capacity as well as reduce inflammation in sulfur mustard-exposed monocytes. Pulm Pharmacol Ther 2010, 23:97-106.

doi:10.1186/1465-9921-15-72

Cite this article as: Liang et al.: Impaired macrophage phagocytosis of bacteria in severe asthma. Respiratory Research 2014 15:72.

\section{Submit your next manuscript to BioMed Central and take full advantage of:}

- Convenient online submission

- Thorough peer review

- No space constraints or color figure charges

- Immediate publication on acceptance

- Inclusion in PubMed, CAS, Scopus and Google Scholar

- Research which is freely available for redistribution 